\section{Magical thinking}

So, 2021 was supposed to be the big reset--as if by flipping the calendar, it would erase the chaos that came before, a vitriolic president, economic downturn, social unrest, and a pandemic would all be swept away by the panacea of the bright new year with its promise of a new president and widespread vaccines.

$\mathrm{Hmm}$.

I write this in January for publication in March (which always requires a bit of a crystal ball), but I cannot see, even now, that 2021 is all roses. In the first week, it has seen a riot in the Capitol and rising COVID-19 numbers (and this before most universities have welcomed students back from their travels).

Wishing it is so doesn't seem to make a positive difference, then why does the opposite seem to be the case? Why does making a statement or assertion about something not occurring seem to invite that very thing? For example, in late 2016, a colleague said, "There's no way will Trump win!"

<crickets chirping>

I am not very superstitious, but like many others, some experiences can be cautionary.

To illustrate (and this is a true story, as embarrassing to me as it may be):

A few years ago, the new director of Preservation in the Libraries was touring each of the branches to offer advice, answer questions, and make sure there was a preservation plan and materials for common library issues. We were happy to take the plastic envelopes to put moldy or spiked books in and to plan for various disasters. In a discussion about the possibility of pipes bursting or another water disaster, I expressed my confidence that this could not happen (famous last words).

You see, the branch library I work in was and is, on the first floor, and the books are in an interior room with walls about 3-feet thick (it is the place we seek shelter when there is a tornado warning). This is because above the library was the presidential apartment of George and Barbara Bush, which, at the time, had assistants and secret service and staff to make sure everything ran smoothly and was in tip-top shape.

So, I told our head of Preservation that the Bush Foundation and staff kept everything perfect for the former president, so what could happen?

$<$ cue the crickets>

Less than six months later, I walked into the branch library early in the morning to hear the slap of water on a surface. Running into the library, I see a leak (more like a waterfall, really). Fortunately, no books were in the line of fire (so to speak), but some lab computers got hit. Realistically, there was nothing we could have done to stop this incident from occurring, but I mean, what are odds? (Note: another phrase that seems to tempt fate.)

Even though there was not really a way to avoid it, I still felt pretty stupid. While this is a prime example of magical thinking, it did provide an object lesson that hubris is not just for Greek tragedies.

Just what does this mean for 2021?

For me, it means that I am going to be careful to check my assumptions and to continue to hope for the best (and try to help realize it), while still preparing for the worst (and doing what I can to minimize or mitigate it).

For the journal, it means that the Editorial Board and I will be working to keep moving the journal forward-finalizing a data policy that was under development late last year, incorporating an option for open review, expanding our reviewer expertise to address growing topics, such as artificial intelligence and methods such as systematic reviews, ethnographic studies and more.

Another area of exploration, prompted by a signed letter from several readers, is registered reports. This topic was explored in the January editorial, which was guest authored by Amy Riegelman, who discusses the value of registered reports for purposes of research quality and author development. 
The March issue is also packed with compelling articles, some addressing controversial and sensitive topics:

"Framing Outcomes and Programming Assessment for Digital Scholarship Services: A Logic Model Approach” by Meris Mandernach Longmeier and Sarah Anne Murphy. Assessing digital scholarship services offered either through academic libraries or elsewhere on campuses is important for both program development and service refinement. Digital scholarship support is influenced by fluid campus priorities and limited resources, including staffing, service models, infrastructure, and partnership opportunities available at a university. Digital scholarship support is built upon deep, ongoing relationships, and there is an intrinsic need to balance these time-intensive collaborations with scalable service offerings. Therefore, typical library assessment methods do not adequately capture the sustained engagement and impacts to research support and collaboration that come from digital scholarship services. This article discusses the creation of a logic model as one approach to frame assessment of digital scholarship services in the university environment.

"Comparing Use Terms in Spanish and US Research University E-Journal Licenses: Recent Trends” by Juan-Carlos Fernández-Molina, Kristin R. Eschenfelder, and Alan P. Rubel. This paper describes the results of a study to compare contemporary e-journal licenses from two research universities in the United States and Spain in terms of e-reserves, interlibrary loan, text and data mining, authors' rights and treatment of copyright exceptions, usage statistics, governing law, data privacy, and obligations entailing security. The data include a higher proportion of scholarly society and academic press publishers than earlier license analyses. This analysis compares license terms over time, across publisher types, and between the two libraries, and it compares findings with recommendations from model licenses. The results show progress toward model license goals in some areas, but deficiencies in others, including self-archiving, usage statistics clauses, and clauses related to e-resource data privacy and library security and disciplinary obligations. Our findings also raise questions about international ILL and governing venue clauses in library licenses outside the North American context.

"University Libraries as Advocates for Latin American Indigenous Languages and Cultures" by Kathia S. Ibacache. The revitalization of Latin American indigenous languages started many years ago, but only some university libraries in the United States have taken steps to advocate for preservation, access, inclusion, and diversity through collection building covering these languages and cultures. This study examines holdings of Quechua, Nahuatl, Guaraní, Zapotec, Maya, Mapudungun, and Aymara materials in 87 university libraries in the United States. This study seeks to answer the question: Are university libraries in the United States supporting inclusion and diversity through the purchase of Latin American indigenous language materials? In addition, the author explores what initiatives university libraries could take to further the revitalization and advancement of these indigenous languages.

"Aha Moments and Continued Confusion: An Analysis of Threshold Concepts through Student Reflections in the ACRL Framework" by Nicole C. Eva, Marissa S. Rocca, and D. Bruce MacKay. With the advent of the ACRL Framework for Information Literacy for Higher Education in 2015, librarians everywhere have tried to adapt their existing information literacy sessions to incorporate the revised concepts. This article discusses how the librarian responsible for a series of four labs in a first-year course reformed the lab content around the six ACRL frames. Student reflections from three semesters' worth of classes were analyzed for content related to each of the six frames, as well as for areas of enlightened understanding (evidence of crossing a threshold into higher understanding, as first outlined by Meyer and Land, 2003) and continued confusion, 
with applicability for all instructors trying to incorporate the frames.

"Collection Development in the Era of Big Deals" by Philippe Mongeon, Kyle Siler, Antoine Archambault, Cassidy R. Sugimoto, and Vincent Larivière. Drawing on an original methodology using citations, downloads, and survey data, this paper analyzes journal usage patterns across 28 Canadian universities. Results show that usage levels vary across disciplines and that different academic platforms varied in their importance to different institutions, with for-profit platforms generally exhibiting lower usage. These results suggest economic inefficiencies exist in "big deal" academic journal subscriptions for universities, as most journals in such bundles are seldom or never used. We recommend that universities coordinate resource sharing and negotiate strategies with academic journal expenditures based on shared interests and usage trends.

"Sexual Harassment at University of California Libraries: Understanding the Experiences of Library Staff Members" by Jill Barr-Walker, Courtney Hoffner, Elizabeth McMunn-Tetangco, and Nisha Mody. In the first study measuring sexual harassment experiences of academic library employees at a single institution, we conducted a census of 1,610 nonstudent employees at the 10-campus University of California Libraries system. This anonymous online survey measured how sexual harassment was experienced and observed in terms of behaviors, exhibitors, reporting and disclosure, institutional support and betrayal, and recommendations for future actions. Out of 579 respondents, 54\% experienced and/or observed sexual harassment at work. Respondents recommended training, workplace culture change, support from leadership, and clear reporting processes in order to address sexual harassment at University of California Libraries.

"They Seek but Do They Find? Investigating the Financial Information-Seeking Behavior of College Students" by Alyson Vaaler, Lauren Reiter, and Ashley E. Faulkner. This paper reports the findings of a survey administered to a large academic university student population, assessing students' self-reported motivations, difficulties, and methods used in finding and using financial information. Results discussed include information types and sources students consult for financial information. The survey also explored students' perceptions of the relative ease of finding financial information and the degree of success students had in finding appropriate information. These results are relevant for librarians who support financial literacy through collection development or one-on-one patron support, or who are involved in developing financial literacy programs for libraries. 22

\section{ACRL Off-RoadShows \\ ACRL's traveling RoadShow \\ workshops are on hold until \\ it's safe to resume large in-person gatherings, but we're working to bring you the same great content through virtual experiences. \\ Learn more at ala.org/acrl/offroad.}

